\title{
Thermal Degradation Kinetics and Lifetime Prediction of Cellulose Biomass Cryogels Reinforced by its Pyrolysis Waste
}

\author{
Lídia K. Lazzari ${ }^{a *}$ (1), Roberta M. Neves ${ }^{a}$, Andrielen B. Vanzetto ${ }^{b}$,Ademir J. Zatterac, \\ Ruth M. C. Santana ${ }^{a}$

\begin{abstract}
${ }^{a}$ Universidade Federal do Rio Grande do Sul, Programa de Pós-Graduação em Engenharia de Minas, Metalúrgica e de Materiais, Av. Bento Gonçalves, 91501-970, Porto Alegre, RS, Brasil.

${ }^{b}$ Pontifícia Universidade Católica do Rio Grande do Sul, Programa de Pós-Graduação em Engenharia

e Tecnologia de Materiais, Av. Ipiranga, 90619-900, Porto Alegre, RS, Brasil.

'Universidade de Caxias do Sul, Pós-Graduação em Engenharia de Processos e Tecnologias, 95070-490, Caxias do Sul, RS, Brasil.
\end{abstract}

Received: September 9, 2021; Revised: December 7, 2021; Accepted: January 19, 2022

\begin{abstract}
Degradation kinetics is an important tool in order to understand and improve energy conversion and the final application of a material. Cellulose cryogels (CC) are a new class of materials that can be reinforced by several types of particle, including biochar. Apart from it, degradation kinetics and lifetime prediction of biomass cellulose cryogels reinforced by cellulose pyrolysis waste (BC) has been investigated using TG techniques and iso-conversional model free methods. Additionally, the same study was applied to cellulose cryogels reinforced by graphene nanoplatelets (NPG) to compare the behavior of a filler from waste (BC) and a noble filler (NPG). Furthermore, the influence of the addition of the fillers into the cellulose biomass were evaluated in terms of thermal stability and crystallinity. BC and GNP led to higher values of activation energies $\left(E_{a}\right)$ calculated from modelfree isoconversional methods and all samples degraded in two-steps. Finally, lifetime prediction was successfully applied and the CC cryogel became more stable over time, maintaining almost $80 \%$ of the mass for 1 year exposed at $180{ }^{\circ} \mathrm{C}$. The results of this study shown that only cellulose biomass cryogels are more suitable to produce thermal insulators due to it higher thermal stability.
\end{abstract}

Keywords: Cryogels, biochar, graphene nanoplatelets, cellulose, degradation kinetics.

\section{Introduction}

The use of porous materials from biomass presents an alternative to polymers derived from fossil fuels such as polystyrene, polyurethane and, ethylene vinyl-acetate foams. Cellulose-based cryogels are a relatively new class of porous materials produced by replacing the liquid phase present in a gel with air (through freeze-drying or freezedrying), without affecting its three-dimensional structure ${ }^{1}$.

These materials have characteristics such as high surface area and porosity, and therefore, they can be used in different areas. A potential application, according to recent studies, for cryogels is the use as thermal insulators ${ }^{2-6}$ for the fact that its thermal conductivity $\left(<0.04 \mathrm{~W} \mathrm{~m}^{-1} \mathrm{~K}^{-1}\right)^{2,7}$ is close to the thermal conductivity of stagnant air $\left(\sim 0.025 \mathrm{~W} \mathrm{~m}^{-1} \mathrm{~K}^{-1}\right)^{8}$. Additionally, they can be reinforced by fillers such as its pyrolysis waste (biochar), in order to improve some properties such as flame resistance, high electrical conductivity, and impermeability to water.

Thermal insulators reduce heat transfer between two media through conduction, convection, and radiation. The insulating capacity of a material is measured according to the thermal conductivity, that is, the lower the thermal conductivity

*e-mail: lidia_lazzari@yahoo.com.br the greater the insulating capacity9. They can be applied in different areas, such as civil construction, textile industry, among others. In some applications, thermal insulators are exposed to high or low temperatures, for example, in heat exchangers where there are heated pipes, or in cold rooms for cooling and preserving food and medicines. For this reason, understand the kinetic degradation behavior is extremely important since there is a change in the temperature during shipping ${ }^{10}$.

Since cryogels might be applied as thermal insulants, understanding the thermal degradation and kinetics behavior is highly recommended. Thermal insulants might use in different environments and thermal conditions, and, consequently, thermal degradation can occur at different rates. Additionally, knowledge on the degradation kinetics on thermal insulant predicts the long-exposure behavior of the sample, saving uptime and cost. Kinetic studies give essential information such as activation energy (minimum energy required to start the reaction), pre-exponential factor (velocity of the reaction) and, reaction order (degradation mechanism) $)^{11-13}$.

For a reliable and complete kinetic study, the ICTAC (International Confederation for Thermal Analysis and Calorimetry) states that the study must follow the steps: 
(i) determination of the dependency of Ea and A with the $\alpha$; (ii) determination of degradation model, and finally, (iii) determination of the $f(\alpha)$. For step (i), isoconvertional model-free methods such as Friedman (FR) and KissingerAkahira-Sunose (KAS) have been applied ${ }^{13-15}$.

For steps (ii) and (iii), F-test tools have been applied, instead of Criado's method. The main drawbacks of Criado's method could be found elsewhere ${ }^{13,16}$. F-test tools are powerful tools to determine reliable kinetics parameters of single- and multi-step degradation mechanisms since they determine them statistically. However, it is noteworthy that researchers handling this kind of tool must have previous knowledge of the degradation behavior of the sample, otherwise, F-test tools become very handful ${ }^{17-19}$. F-test tools were applied on silanized microcrystalline cellulose ${ }^{12}$, nanocellulose reinforced composites $^{16}$, polyurethane ${ }^{20}$, epoxy resins ${ }^{21}$, poly(ethylene oxide $)^{18}$, lignocellulosic fibers ${ }^{22}$, tire rubber ${ }^{23}$, among others.

As seen in our previous studies, cellulose/biochar cryogels can be used as thermal insulators ${ }^{2}$ use to their low thermal conductivity. Besides, the biochar has the potential to replace carbon structures ${ }^{24}$, such as graphene nanoplatelets, in cellulose cryogels. With thermal insulation as an application, cellulose cryogels would be exposed to variations in temperature and weather, so it is important to know the behavior of this material if exposed to these conditions. Therefore, within this context, the present work aims to study the degradation kinetics of cellulose/BC and cellulose/GNP cryogels, to determine the degradation mechanisms of these materials. In addition to assessing the influence of the addition of biochar and GNP on these mechanisms and also on the crystallinity of cryogels, to investigate the possibility of replacing GNP's with biochar. To the best of our knowledge, there is no mention regarding the degradation kinetics regarding the influence of carbonaceous fillers in cellulose cryogels.

\section{Materials and Methods}

\subsection{Materials}

The materials used in the production of the aerogels were: Pinus elliotti cellulose (Trombini - RS) and graphene nanoplatelets (GNP) with carbon content $>99.5 \mathrm{wt} \%$ (Strem Chemicals, INC. - USA).

The chemical composition of cellulose was performed. Lignin was determined according to TAPPI T222 om02 . Extractives were determined by TAPPI T204 cm-97. Humidity, cellulose, and hemicellulose were determined by Van Soest Method. All results were determined in percentage by weight $(\% \mathrm{w} / \mathrm{w})$.

\subsection{Production of cellulose/BC and cellulose/ GNP cryogels}

Pinus elliotti cellulose, in solution, was ground in a stone mill for 5 hours at $4500 \mathrm{rpm}$, to obtain the cellulose suspension with $1.43(\% \mathrm{w} / \mathrm{w})$ cellulose fiber concentration.

The biochar (BC) was produced from cellulose pyrolysis with a heating rate of $5^{\circ} \mathrm{C} \mathrm{min}{ }^{-1}$, isotherm time of $60 \mathrm{~min}$, a final operating temperature of $800^{\circ} \mathrm{C}$, and $\mathrm{N}_{2}$ flow of $150 \mathrm{~mL}$ $\mathrm{min}^{-1}$. The cryogels were produced using the methodology presented by ${ }^{24}$. Initially, the cellulose suspension was centrifuged and $\mathrm{BC}$ or GNP was added to the supernatant at concentrations of 50 and $100 \%$ (relative to the cellulose mass), the final concentration of suspension is 2.14 and $2.86 \% \mathrm{w} / \mathrm{w}$, respectively. The supernatant was mixed with the precipitate and mechanically stirred for $5 \mathrm{~min}$ to completely homogenize the suspension. The final suspension was sonicated in a Sonics Sonifier Model VC505 Sonifier for 30 minutes and 50\% amplitude (maximum equipment capacity - 500W). Finally, the suspension was frozen in an ultra-freezer in square molds and then lyophilized for 72 hours under vacuum at $-45^{\circ} \mathrm{C}$.

The samples were named: $\mathrm{CC}$ for the pure cellulose cryogel; CC100BC for cellulose cryogel containing 100\% biochar (relative to the cellulose mass); CC50BC for cellulose cryogel containing $50 \%$ biochar (relative to the cellulose mass); CC100GNP for cellulose cryogel containing 100\% graphene nanoplatelets (relative to the cellulose mass) and CC50GNP for cellulose cryogel containing 50\% nanoplatelets of graphene (relative to the cellulose mass).

\subsection{Characterization of cellulose/BC and cellulose/GNP cryogels}

The analysis was performed on an X-ray diffractometer, Shimadzu - model XRD-6000 (Japan). The range analyzed was $2 \theta=10^{\circ}$ to $40^{\circ}$, with a step of $0.05^{\circ}$ and an integration time of $2 \mathrm{~s}$. The crystallinity of the cryogels was calculated using Equation 1 This method was based on research carried out by Hermans and Weidinger ${ }^{25}$.

$C I=\left(\frac{A_{\text {cryst }}}{A_{\text {total }}}\right) \times 100$

where, $\mathrm{CI}$ is the crystallinity index (\%); $\mathrm{A}_{\text {cryst }}$ is the sum of crystalline peak areas, and, $\mathrm{A}_{\text {total }}$ is the total area under the diffractograms.

The thermal properties were analyzed by thermogravimetric analysis (TG) Shimatzu TGA-50 equipment. Under conditions: $\mathrm{N}_{2}$ atmosphere $50 \mathrm{~mL} \cdot \mathrm{min}^{-1}$ rate, a heating rate of $10{ }^{\circ} \mathrm{C} \cdot \mathrm{min}^{-1}$ from 30 to $800{ }^{\circ} \mathrm{C}$.

The mass of each sample was ca. $10 \mathrm{mg}$. From TG curves, a theoretical study based on the chemical composition of Pinus eliotti (base of the cryogel) was performed based on Cabeza et al. ${ }^{26}$ work. We choose to apply this approach since it allows observing the effect of each component on the TG curve and the evolution of each component's char. The free spreadsheet developed (Biomass Modelling - Thermal degradation) is available at http://hpp.uva.es/software/.

For kinetic study, were four different heating rates were used in TG curves: $5,10,20$, and, $40{ }^{\circ} \mathrm{C} \mathrm{min}{ }^{-1}$, with temperatures ranging from 30 to $800{ }^{\circ} \mathrm{C}$ and $\mathrm{N}_{2}$ atmosphere $50 \mathrm{~mL} . \mathrm{min}^{-1}$ rate. The kinetic study was followed by Vyazovkin studies ${ }^{27,28}$. Four steps were used for a complete kinetic degradation study. Firstly the Arrhenius parameters, activation energy ( $\boldsymbol{E}_{\boldsymbol{a}}$ ) and pre-exponential factor (A) were calculated by two isoconversional methods: differential Friedman (FR) (Equation 2) and integral Kissinger-AkahiraSunose (KAS) (Equation 3), in which R and T are the gas constant (8.314 J.K.mol $\left.{ }^{-1}\right)$ and temperature $(\mathrm{K})$, respectively.

$\ln \left(\frac{\boldsymbol{d}}{\boldsymbol{d} \boldsymbol{t}}\right)=\ln (\boldsymbol{A f}(\alpha))-\frac{\boldsymbol{E} \boldsymbol{a}_{\boldsymbol{F R}}}{\boldsymbol{R T}}$ 
$\ln \left(\frac{\beta}{T^{2}}\right)=\ln \left(\frac{A R}{E(\alpha)}\right)-\frac{E a_{K A S}}{R T}$

Where $\mathrm{A}$ is the pre-exponential factor, $\mathrm{E}$ is the activation energy, $\alpha$ is the fractional reaction, $\mathrm{R}$ is gas constant and, $\mathrm{T}$ is the temperature.

Once $\boldsymbol{E}_{\boldsymbol{a}}$ and A values were determined, the second step was determined by the degradation model followed by determining the degradation mechanism(s) $(\boldsymbol{f}(\alpha))$. Last but not least, a prediction of properties for 10 years regarding loss mass at different temperatures were analyzed. All kinetic parameters and prediction of properties were simulated in the Thermokinetics software, from Neztsch. More information about the software could be found elsewhere ${ }^{12,18,22}$.

After that, lifetime prediction was done based on the previously obtained kinetic parameters used by the Thermokinetics Software. Lifetime prediction is performed in order to predict the behavior of the material when exposed to certain temperatures for long periods of time ${ }^{16}$. More information regarding the steps could be found elsewhere.

\section{Results and Discussion}

\subsection{Cellulose chemical composition}

Pinus Elliotti cellulose had about $68.4 \pm 2.1 \%(\mathrm{w} / \mathrm{w})$ cellulose, $14.2 \pm 1.4 \%(\mathrm{w} / \mathrm{w})$ hemicellulose, $3.9 \pm 0.6 \%(\mathrm{w} / \mathrm{w})$ lignin, $10.62 \pm 0.3 \%(\mathrm{w} / \mathrm{w})$ extractives, and $7.43 \pm 0.19 \%$ $(\mathrm{w} / \mathrm{w})$ moisture. The results were calculated considering the biomass in natura (wet basis). The sum of the four fractions does not reach $100 \%$. This behavior could be related the presence of other substances that are determined by none of the methods used ${ }^{29}$. After wood processing for cellulose production, cellulose content increases and lignin decrease $\mathrm{s}^{30}$, however, for the present sample, there is the presence of lignin in its composition because this material press has not gone through the fiber bleaching process. According to ${ }^{30}$ the mechanical and physical properties of the fibers are influenced by their composition, higher levels of crystalline cellulose provide greater thermal stability. Fibers with higher levels of hemicellulose and extracts show thermal degradation at low temperatures, because they can absorb more moisture.

Based on the aforementioned chemical composition, Figure 1 shows the representative curve for $5{ }^{\circ} \mathrm{C} \mathrm{min}^{-1}$, where the TG curve was decomposed into the components: water, extractives, hemicellulose, cellulose, lignin, and their respective chars according to Cabeza et al. ${ }^{26}$. Cabeza and co-workers developed a free spreadsheet ${ }^{26}$ in which the TG curves can be estimated from the initial chemical composition of the vegetal fiber and taking into account the formation of cellulose, hemicellulose, and lignin chars. Based on the software water, extractives, cellulose, cellulose char, hemicellulose, hemicellulose char, lignin, and lignin char, can be individually studied without the interference of the others, giving an insight into the role of the individual component in the degradation curve ${ }^{22}$. This approach was applied only to the raw material (Pinus eliotti). The literature widely applied Waterloo's degradation model for vegetal fibers. The model states that all solids decompose into volatiles and char $^{12,22,26}$.

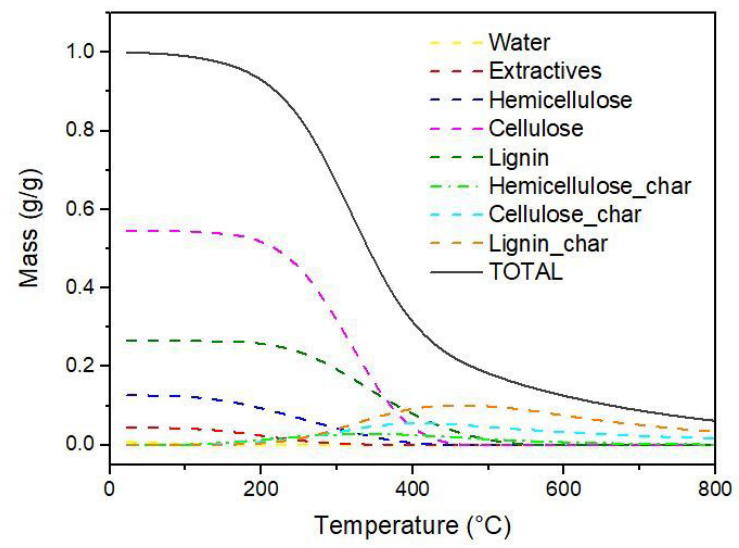

Figure 1. Representative curve simulated with a heating rate of $5^{\circ} \mathrm{C} \min ^{-1}$ for Pinus eliotti, using Cabeza's approach.

It is noteworthy that the lignin, when degraded, forms the highest amount of char between the components.

Literature reports the thermal degradation of lignocellulosic materials in the following order: around $100^{\circ} \mathrm{C}$ (elimination of water/humidity), around $200^{\circ} \mathrm{C}$ (degradation of hemicellulose), around $270{ }^{\circ} \mathrm{C}$ (degradation of cellulose) and, around $400{ }^{\circ} \mathrm{C}$ (degradation of lignin) $)^{31-33}$. All the results presented in Figure 1 corroborates with the literature. Furthermore, some authors report that hemicellulose is the main responsible for the reaction order and thermal stability, cellulose for the degradation process and the Arrhenius parameters $\left(\mathrm{E}_{\mathrm{a}}\right.$ and A) and, lignin for the final tail ${ }^{11,22,34,35}$.

\subsection{XRD and Crystalinity Index}

Figure 2(a) shows the X-ray diffractograms of cellulose and cryogels samples studied. Cellulosic materials present $2 \theta$ reflection assigned in $14.4^{\circ}\left(\begin{array}{lll}1 & -1 & 0\end{array}\right), 16.3^{\circ}\left(\begin{array}{lll}1 & 1 & 0\end{array}\right), 22.3^{\circ}$ ( $\left.\begin{array}{lll}2 & 0 & 0\end{array}\right)$ and, $34.3^{\circ}\left(\begin{array}{lll}0 & 0 & 4\end{array}\right)$ diffraction patterns of carbon crystallographic plane, and the $18.6^{\circ}$ reflection assigned to the amorphous phase. These plans are characteristic of native cellulose $\mathrm{I}^{36,37}$.

Figure 2 (b) shows the diffractogram of the biochar and the cellulose/BC cryogels. The BC spectrum shows a strong broad diffraction peak at around $22^{\circ}$ which is in keeping with the $\left(\begin{array}{lll}0 & 0 & 2\end{array}\right)$ diffraction patterns of carbon ${ }^{38}$. As is already known, crystalline cellulose disappears during biomass pyrolysis. The peak at $29.3^{\circ}$ in the spectra of cellulose/ $\mathrm{BC}$ cryogels, according to ${ }^{39}$ is related to the characteristic graphite d-spacings that occur close to the $27^{\circ}$. Also, the d-spacings present fewer contrasts in the biochar compared to the raw material, which influences the spectra of cryogels due to the high concentration of biochar present in them, as there is an increase in the aromatization of the biochars' molecular structures together with the crystalline crysta ${ }^{39}$. The cellulose/biochar cryogels XRD pattern is dominated by the crystalline cellulose in the original biomass ${ }^{40}$. According to the diffractograms, the BC sample seems amorphous because the crystalline peaks are very wide, whereas the CC50BC and CC100BC samples present the crystalline and narrow peaks. 
The XRD spectra of cellulose/GNP cryogels shown in Figure 2 (c), show the same pattern as the GNP spectrum, with a peak at $\sim 26^{\circ}$ associated with stacked crystalline graphitic sheets or bulk graphite ${ }^{41}$. Cryogels show a weakening of this peak after the incorporation of GNPs, because the mass of GNP decreases when it is added to cellulose, which reflects a decrease in the degree of graphitization of cryogels $\mathrm{s}^{41,42}$.

The crystallinity index (Figure 2 (d)) of Pinus elliotti cellulose, calculated by Equation 1, was $79.9 \%$, a value consistent with the literature ${ }^{25,37}$. The cryogel crystallinity index is affected by the addition of the BC and GNP. CC50BC and CC100BC cryogels had a lower I.C. than CC50GNP and CC100GNP cryogels, which is expected since GNPs have peaks typical of crystal structures (Figure 2c).

\subsection{Thermogravimetric analysis}

According to the thermogravimetric curves, at heating hate of $10^{\circ} \mathrm{C} \mathrm{min}^{-1}$, all samples showed a loss of mass around $100^{\circ} \mathrm{C}$, due to the loss of moisture present in them. Figure $3 \mathrm{a}$ shows the TG and DTG curves for cellulose, BC, and GNP. Cellulose presents the greatest loss of mass between $280-400^{\circ} \mathrm{C}$ : degradation of the most reactive fraction of hemicellulose $\left(150-350^{\circ} \mathrm{C}\right)$, generating more non-combustible gases and more tar than cellulose; cellulose degradation (275$350^{\circ} \mathrm{C}$ ) responsible for the greater production of flammable volatiles; and degradation of lignin. In the case of lignin $\left(250-500^{\circ} \mathrm{C}\right)$, due to its highly complex structure, as it is a

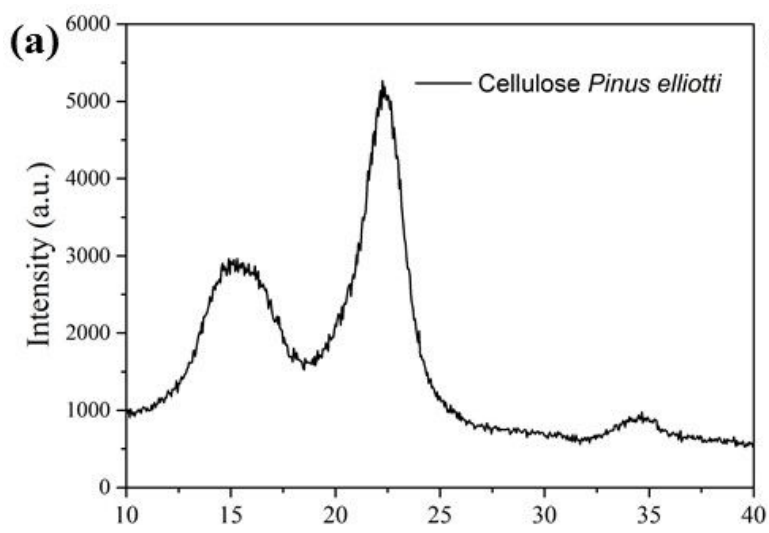

(c)

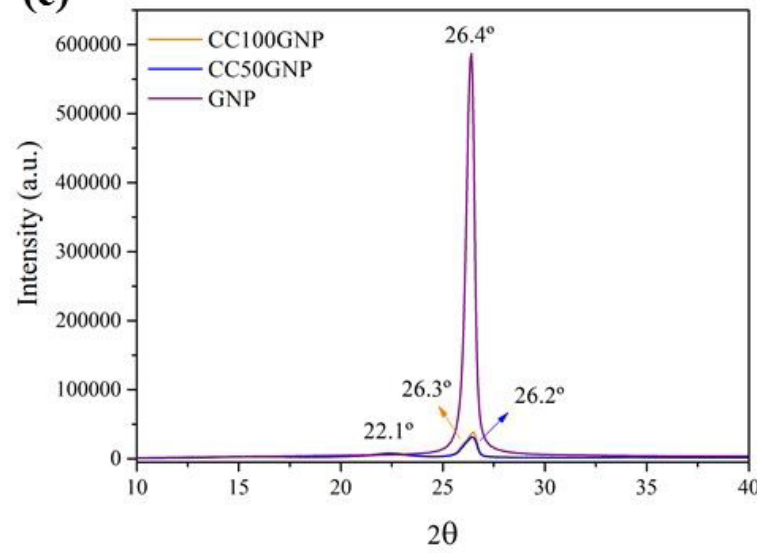

heterogeneous polymer, its crosslinking occurs in different ways, this is because lignin is derived from lignol precursors. Due to this, lignin has different stabilities, which directly reflects on its degradation behavior ${ }^{43-47}$. Even starting at low temperatures, the degradation process occurs more slowly, so lignin is the main responsible for the formation of residual material $(17.3 \%)^{1,37,43}$. The BC and GNP showed a loss of mass below $10 \%$ (4.2 and $7.2 \%$, respectively), referring to the humidity present in the sample. The organic matter present in the cellulose is degraded during the pyrolysis process, for this reason, there is no considerable loss of mass in the BC sample.

For CC, CC50GNP, and CC100GNP (Figure 3bdf) it was possible to observe one main degradation peak. For all cryogels, the biggest event of mass loss occurs between $300-400{ }^{\circ} \mathrm{C}$ referring to the degradation of the major compounds (cellulose, hemicellulose, and lignin) of the cellulose used as raw material, as mentioned above. The incorporation of GNP to the cellulose cryogel, presented Tpeak value within the error range of the equipment, which shows that GNP did not change the thermal stability of cryogels. This behavior is also observed by ${ }^{42}$ for graphene oxide/cellulose aerogels nanocomposite. In the study presented by ${ }^{48}$ you hear an increase of $20^{\circ} \mathrm{C}$ in Tonset with the addition of $5 \%$ of GO in the regenerated cellulose/graphene oxide composite aerogel due to the strong interaction between the two raw materials

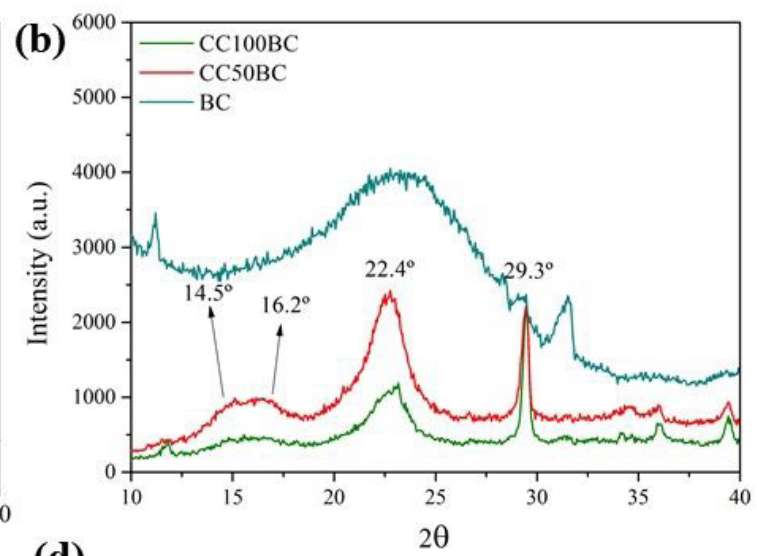

(d)

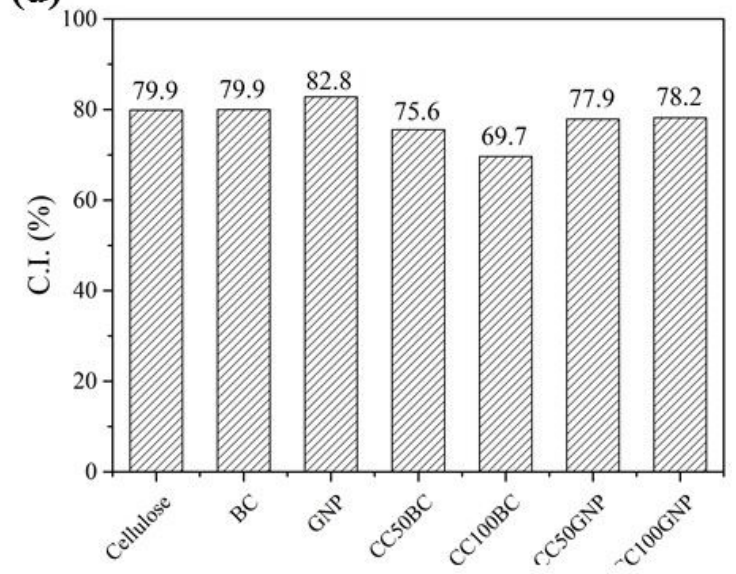

Figure 2. X-ray diffractograms: (a) cellulose Pinus Elliotti; (b) cellulose/BC cryogels; (c) cellulose/GNP cryogels and, (d) crystalline index. 
(a)

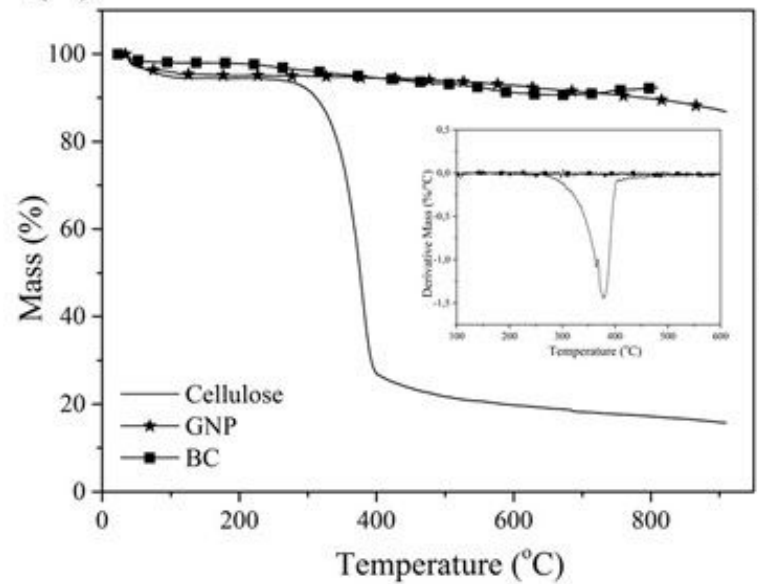

(c)

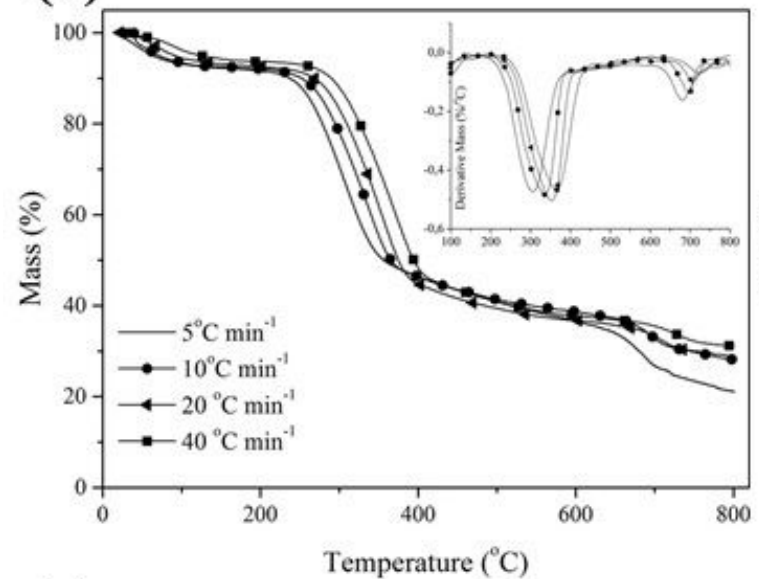

(e)

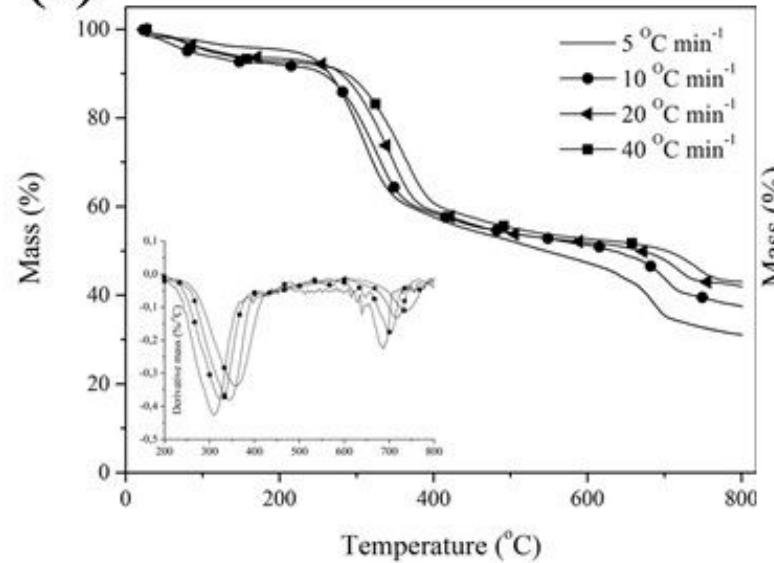

(b)

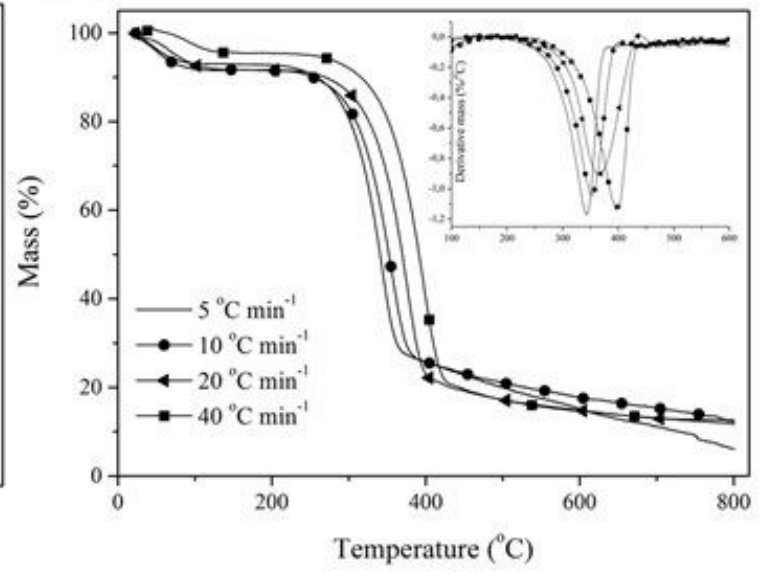

(d)

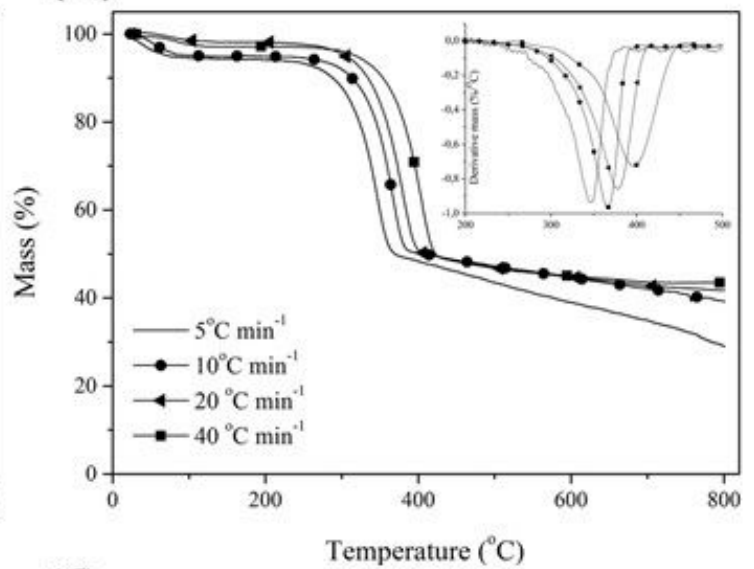

(f)

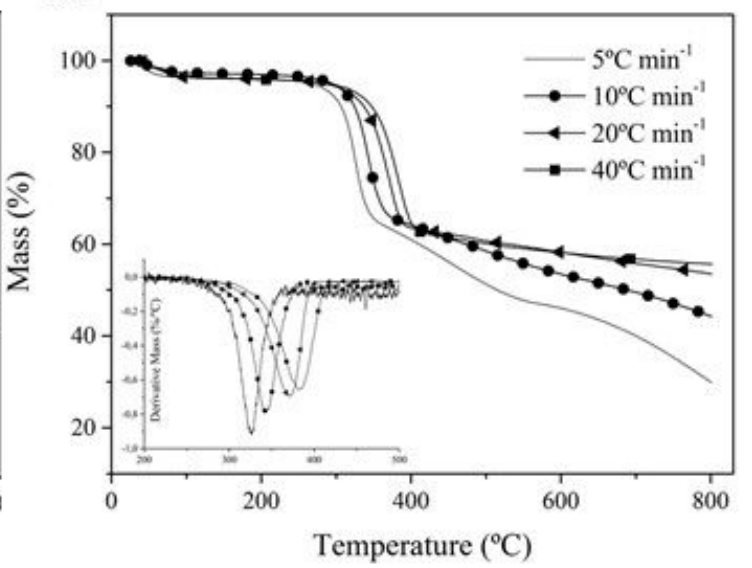

Figure 3. TGA curve and its derivative (DTG) for (a) cellulose, BC, and GNP; (b) CC; (c) CC50BC; (d) CC50GNP; (e) CC100BC and, (f) CC100GNP.

forming the network reticulation three-dimensional effect of aerogel limiting the molecular activities of cellulose.

After the decomposition of lignin, the biochar formation process is completed. As the temperature rises, from that point on, there is the formation of ashes ${ }^{49}$. In this stage, there is a low loss of mass because the main components of the raw material have already been decomposed. This behavior was evidenced only for cryogels CC50BC and $\mathrm{CC} 100 \mathrm{BC}$ (Figure $3 \mathrm{c}$ and $3 \mathrm{e}$ ) cryogels that presented the second degradation peak, around $600-750{ }^{\circ} \mathrm{C}$. 
Table 1 shows the data taken from Figure 3 for the TG curves of cryogels, for the heating rate of $10{ }^{\circ} \mathrm{C} \mathrm{min}^{-1}$. The residual masses of BC and GNP were 95.8 and $92.8 \%$, respectively. The residual mass showed an increase of about 2-4 times of the cryogels to the cellulose and is associated with the inorganic compounds present in the BC and GNP.

\subsection{Degradation kinetics and lifetime prediction}

All the kinetic study reported here was based on the simulation of the samples from 100 to $500{ }^{\circ} \mathrm{C}$, based on Figure 3 (TG) in which shows that the range is the main degradation. Additionally, at temperatures higher than $500{ }^{\circ} \mathrm{C}$ the char reside takes place, and our objective was to observe the influence of carbonaceous fillers on the degradation of cellulose cryogel. Regarding degradation kinetics, The TG and DTG curves obtained at four different heating rates (5,
10,20 , and $40{ }^{\circ} \mathrm{C} \mathrm{min}^{-1}$ ) and the simulated curves for the most probable degradation mechanisms, based on the bestfit curves and the statistics of these curves are displayed in Supplementary Material, for all cryogels.

As stated by ICTAC, the first step of the degradation kinetics is the determination of the dependency of $E a$ and A with the conversion degree $(\alpha)$, and this relation is showed in Figure 4 . The shape of all curves (Figure 4 ) are very similar and linear (for $\alpha=0.2-0.7$ ), and the same behavior was reported by Neves et al. ${ }^{12}$ and Ornaghi et al. ${ }^{22}$. The linearity observed for all samples corresponds to a non-dependency of $E a$ and A with $\alpha$. The $\alpha=0.2$ to 0.7 range is reported in the literature as the main degradation step of cellulosic materials ${ }^{11,26}$.

Table 2 summarizes the mean values of $E a$ samples evaluated Friedman method (differential) and KAS method (integral) for $\alpha=0.2$ - 0.7. An ANOVA one-way was performed

Table 1. TG values extracted from Figure 3, for the heating rate of $10{ }^{\circ} \mathrm{C} \mathrm{min}^{-1}$.

\begin{tabular}{cccccccc}
\hline \multirow{2}{*}{ Sample } & \multicolumn{7}{c}{$\mathrm{TG}$} \\
\cline { 2 - 8 } & $\mathrm{T}_{\text {onset }, 1}\left({ }^{\circ} \mathrm{C}\right)$ & $\mathrm{T}_{\text {peak }, 1}\left({ }^{\circ} \mathrm{C}\right)$ & $\mathrm{T}_{\text {offset }, 1}\left({ }^{\circ} \mathrm{C}\right)$ & $\mathrm{T}_{\text {onset }, 2}\left({ }^{\circ} \mathrm{C}\right)$ & $\mathrm{T}_{\text {peak }, 2}\left({ }^{\circ} \mathrm{C}\right)$ & $\mathrm{T}_{\text {offset }, 2}\left({ }^{\circ} \mathrm{C}\right)$ & $\mathrm{RW}^{*}(\%)$ \\
\hline Cellulose & 318.6 & 358.5 & 391.1 & - & - & - & 17.3 \\
\hline CC & 318.6 & 352.7 & 391.0 & - & - & - & 13.8 \\
\hline CC50BC & 282.4 & 333.8 & 369.4 & 674.4 & 697.8 & 709.9 & 28.1 \\
\hline CC100BC & 282.7 & 324.6 & 364.1 & 659.76 & 684.9 & 713.92 & 38.9 \\
\hline CC50GNP & 337.4 & 365.7 & 380.1 & - & - & - & 39.4 \\
\hline CC100GNP & 321.8 & 343.5 & 361.6 & - & - & - & 56.3 \\
\hline
\end{tabular}

*RW - Residual weight
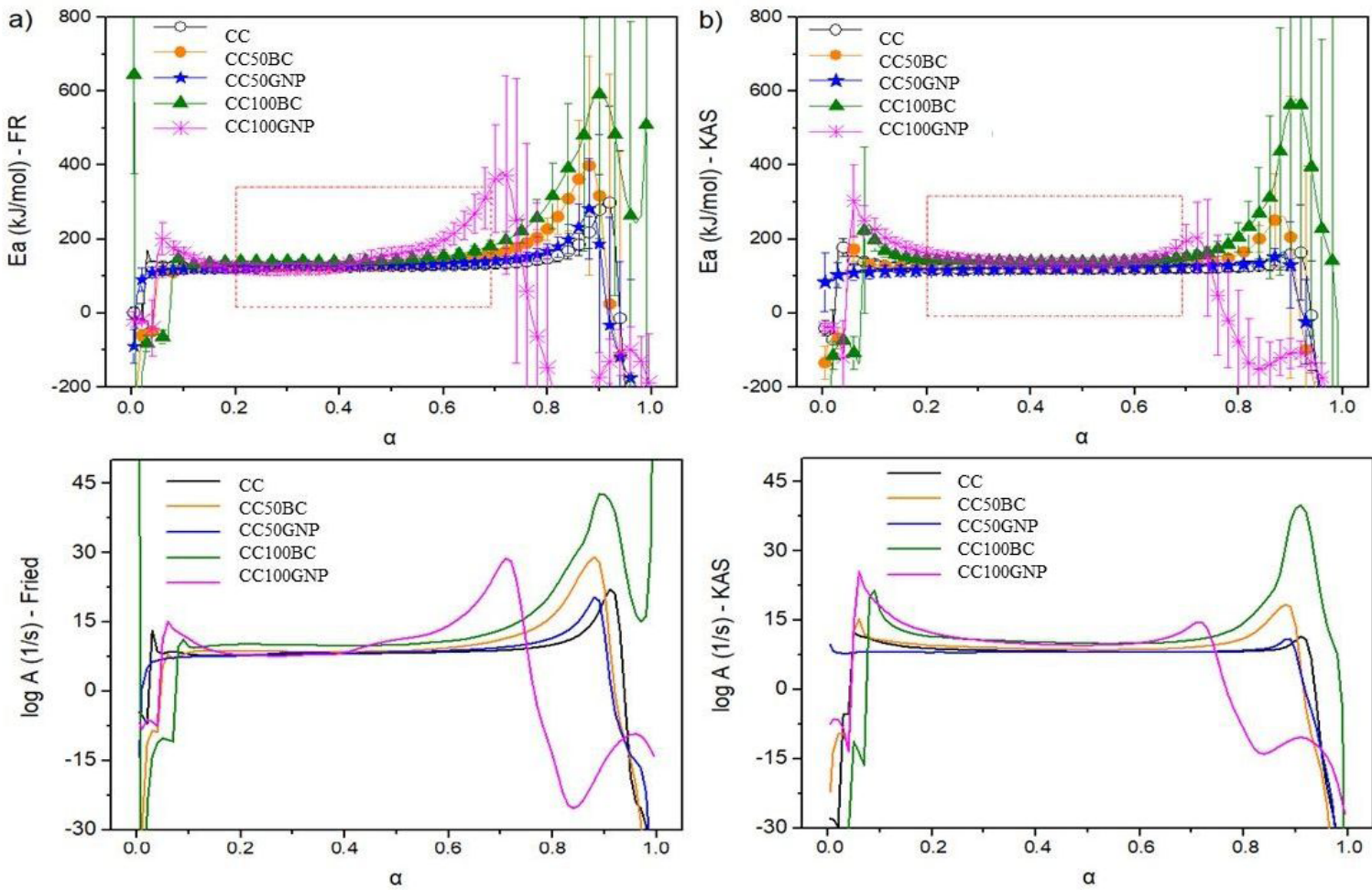

Figure 4. Dependence of Ea vs alfa for all studies samples by a) Friedman method and b) KAS Method. 
Table 2. Mean values of $\left(E_{a}\right)$ and $\mathrm{A}(\alpha=0.2-0.7)$ for all studied samples.

\begin{tabular}{|c|c|c|c|c|}
\hline \multirow{2}{*}{ Sample } & \multicolumn{2}{|c|}{ Friedman } & \multicolumn{2}{|c|}{ KAS } \\
\hline & $E_{a}\left(\mathrm{~kJ} \mathrm{~mol}^{-1}\right)$ & $\log A\left(1 . s^{-1}\right)$ & $E_{a}\left(\mathrm{~kJ} \mathrm{~mol}^{-1}\right)$ & $\log A\left(1 . s^{-1}\right)$ \\
\hline $\mathrm{CC}$ & $126.2 \pm 3.0$ & $8.2 \pm 0.2$ & $119.6 \pm 0.5^{\mathrm{a}}$ & $8.3 \pm 0.2$ \\
\hline CC50BC & $131.3 \pm 9.6$ & $9.0 \pm 0.6$ & $121.1 \pm 2.8^{\mathrm{a}}$ & $8.8 \pm 0.2$ \\
\hline CC50GNP & $129.6 \pm 4.1$ & $8.4 \pm 0.4$ & $120.2 \pm 2.5^{\mathrm{a}}$ & $8.0 \pm 0.1$ \\
\hline CC100BC & $147.7 \pm 11.6$ & $10.4 \pm 0.8$ & $141.6 \pm 3.2^{\mathrm{b}}$ & $10.4 \pm 0.4$ \\
\hline CC100GNP & $165.0 \pm 61.0$ & $11.5 \pm 4.9$ & $145 \pm 12.9^{\mathrm{b}}$ & $10.5 \pm 1.0$ \\
\hline
\end{tabular}

*Same letters indicate no statistical difference between samples in a column (Table S.1 - Supplementary Material).

on $E_{a}$ values for KAS method (Table S.1). Comparing the different samples, the incorporation of higher content of BC and GNP into the cellulose cryogel did influence the kinetic parameters, raising Ea and A values. Neves et al. ${ }^{16}$ studied kinetics degradation of microcrystalline cellulose and the $E_{a}$ value found was around $170 \mathrm{Kj}$ mol-1 for KAS method ${ }^{36}$, studied kinetics degradation of Pinus eliotti and the $E_{a}$ value found was around $180 \mathrm{kj} . \mathrm{mol}-1$ for FWO method, Ali et al. ${ }^{50}$ studied kinetics degradation of coconut shell waste and the $E_{a}$ value found was around $100 \mathrm{~kJ}$ mol-1 for FWO method. We found, for CC sample (100\% cellulose), $E_{a}=119.6 \pm 0.5 \mathrm{~kJ}$ mol-1 by KAS method, supporting the results trustworthiness summarized in Table 2. Its noteworthy that, the Tonset of both $\mathrm{BC}$ samples decrease around $30^{\circ} \mathrm{C}$ in the DTG curves and the Ea values for both were higher, compared to CC samples, Tonset and Ea are not correlated. For instance, Tonset is determined in a specific point (DTG) and the Ea value is determined in a range of conversion degree. By observing Figure $3 \mathrm{c}$ and $3 \mathrm{e}$, is possible to see that T onset was determined around $280^{\circ} \mathrm{C}$ around 0.35 conversion degree whereas the Ea was determined in the conversion degree range of 0.2 to 0.7 .

The plot of Friedman method (Figure S1) and KAS method (Figure S2) considering conversion degree range of $\alpha=0.2-0.7$ for all samples could be found in the Supplementary Information. The second and third steps of a reliable kinetic degradation study, according to ICTAC, are the determination of the degradation model and the determination of the $f(\alpha)$, respectively. The degradation model and degradation mechanism were determined statistically using an F-test tool based on previous studies ${ }^{12,22}$, and the statistic results for the simulated curves (Figure S3) are shown in Supplementary Material. A reaction pathway for the vegetal fiber degradation model was the Waterloo's degradation model, which states that all solid compounds decompose into volatiles and charcoal ${ }^{11,26}$.

Firstly, all the samples were simulated using a onestep model (Figure S4), but a poor fit was obtained for all degradation models. Even though the samples appear to obey a single-step degradation due to its non-dependency of Arrhenius parameters with $\alpha$ as aforementioned, a poor fit indicates that, at least, two degradation mechanisms are present $^{12,13}$. Apart from it, using the best single-step results, a two-step model and mechanisms were tested. Two-step degradation model was chosen based Benini et al. ${ }^{50}$, Ali et al. ${ }^{11}$, Pereira et al..$^{51}$, Hu et al. ${ }^{52}$ and Ornaghi et al. ${ }^{22}$.

For the cryogel $\mathrm{AC}$ the most probable degradation model is $\mathrm{A} \rightarrow \mathrm{B} \rightarrow \mathrm{C}$ where: A seems to be cellulose and or lignin chains, B seems to be low molecular weight cellulose and/or lignin, and C: cellulose and/or lignin chars. For the cryogels produced using carbonaceous fillers (biochar and graphene nanoplates) the most probable degradation model is $A-\quad 1 \rightarrow B$ where: A seems to be cellulose and or lignin chains, $\mathrm{B}$ seems to be low molecular weight cellulose and/or lignin, and C: cellulose and/or lignin chars and BC and GNP chars. Since two-step degradation mechanism was observed, two Ea values need to be reported: $E_{a} 1=141.7 \mathrm{~kJ} . \mathrm{mol}-1$ and $E_{a} 2=100 \mathrm{~kJ} . \mathrm{mol}-1$ for CC, $E_{a} 1=145 \mathrm{~kJ} . \mathrm{mol}-1$ and $E_{a} 2=104 \mathrm{~kJ} . \mathrm{mol}-1$ for CC50BC, and, $E_{a} 1=151.2 \mathrm{~kJ} . \mathrm{mol}-1$ and $E_{a} 2=100 \mathrm{~kJ} . \mathrm{mol}-1$ for CC50GNP, $E_{a} 1=180.3 \mathrm{~kJ} . \mathrm{mol}-1$ and $E_{a} 2=124 \mathrm{~kJ} . \mathrm{mol}-1$ for CC $100 \mathrm{BC}$ and $E_{a} 1=191.2 \mathrm{~kJ} . \mathrm{mol}-1$ and $E_{a} 2=130 \mathrm{~kJ} . \mathrm{mol}-1$ for CC100GNP. The degradation mechanism for all samples was autocatalytic $(\mathrm{Cn})$ followed by random nucleation (Fn) or autocatalytic ( $\mathrm{Cn}$ or $\mathrm{Bn})$. The results reported here corroborate with Ali et al. ${ }^{11}$, Neves et al. ${ }^{12}$, Ornaghi et al..$^{22}$ and Benini e $\mathrm{al}^{50}$

The thermal lifetime predictions of all cryogels were simulated using the $\mathrm{E}_{\mathrm{a}}$, A values and degradation mechanism previously determined and the curves were simulated by one year of exposure at the $30-530{ }^{\circ} \mathrm{C}$ temperature range. This temperature range since thermal insulants can be exposed to a wide temperature range and based on TG curves (Figure 3 ). For a better visualization, was choose to analyze the mass consumption at $180^{\circ} \mathrm{C}$ (Figure 5) for all samples. The sample $\mathrm{CC}$ exposed for 1 year at $180^{\circ} \mathrm{C}$ will lose around $15 \%$ of the mass, whereas the samples CC50BC, CC50GNP, CC100BC, and CC100NP will lose around $80 \%, 80 \%, 100 \%$, and $90 \%$ of mass, respectively, at the same conditions as CC. This means that the incorporation of carbonaceous fillers into the cryogel increased the amount of mass degradation, become harmful in that sense. This behavior could be related to the fact that the sample AC has a certain amount of lignin and hemicellulose (Figure 1). The samples reinforced by carbonaceous fillers have less representative amounts of cellulose, hemicellulose, and lignin, and higher conductive materials i.e. BC and GNP, decreasing the working temperature of those samples. In other words, cellulose, hemicellulose, and lignin act as a barrier to heat transfer whereas BC and GNP act as conductive heat transfer.

It's noteworthy that, simulate the thermal lifetime predictions, is very important since it, is possible to verify the optimum working temperature of the materials versus the time of exposure. In this case, for all samples, is safe to work around $100{ }^{\circ} \mathrm{C}$ for one year of exposure without a premature failure of the material. 
(a)

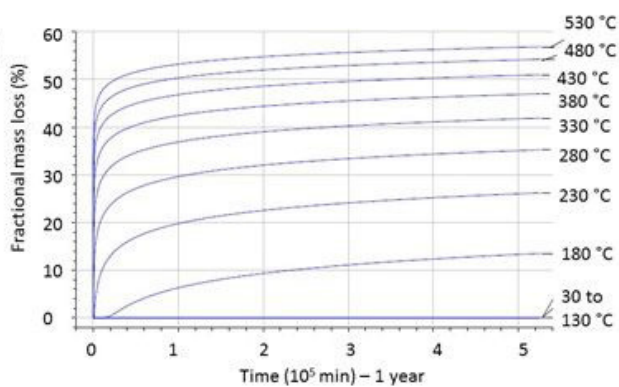

(c)

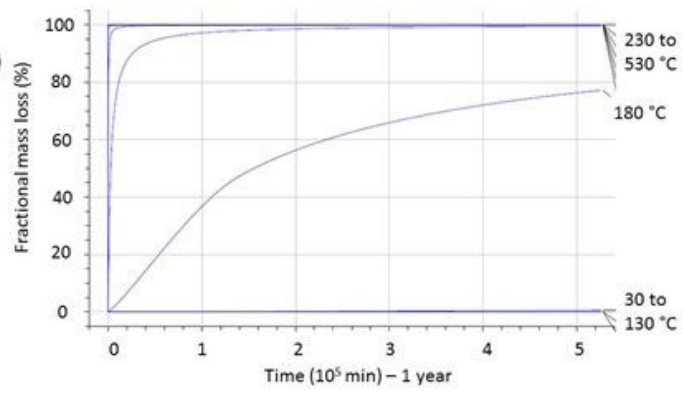

(b)

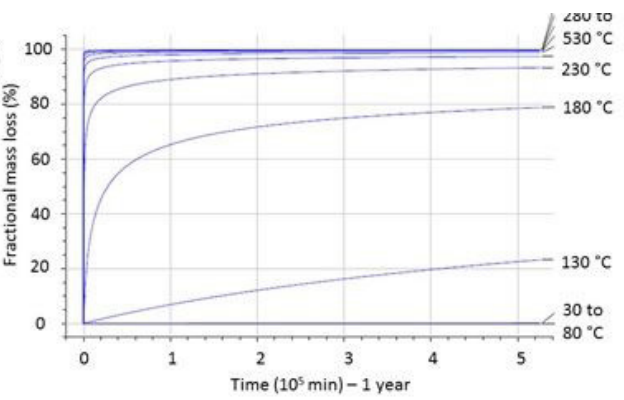

(d)

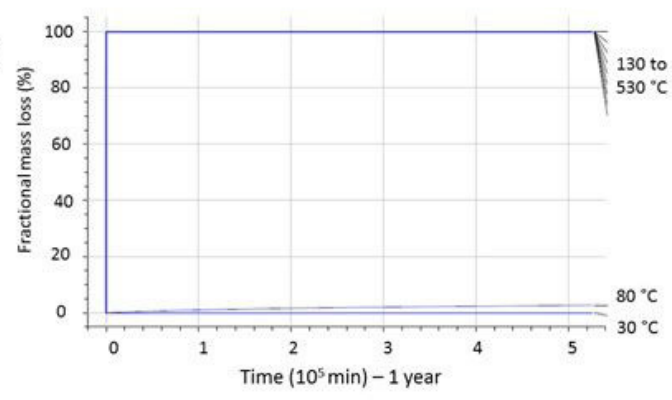

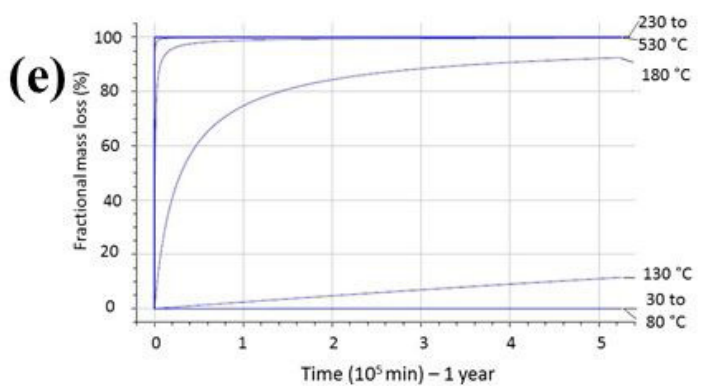

Figure 5. Lifetime prediction all cryogels at different isotherms based on the TG degradation curves: a) CC; b) CC50BC; c) CC50GNP; d) $\mathrm{CC} 100 \mathrm{BC}$, e) CC100GNP.

\section{Conclusions}

Here we report the results of the study of the degradation kinetics of cellulose cryogels with the addition of carbonaceous fillers to verify the influence of these fillers on the degradation and lifetime of cryogels. Cellulose cryogels containing 50 and $100 \%$ of biochar and cellulose cryogels containing 50 and $100 \%$ graphene nanoplatelets were produced. The cryogel crystallinity index was affected by the presence of the carbonaceous particles, assuming higher values with the addition GNP. The incorporation of biochar to cellulose cryogels decreased its degradation temperature, while GNP increased. In the degradation kinetics the degradation mechanism present for all samples was autocatalytic $(\mathrm{Cn})$ followed by random nucleation $(\mathrm{Fn})$ or autocatalytic ( $\mathrm{Cn}$ or $\mathrm{Bn})$. In terms of thermal lifetime prediction, the incorporation of carbonaceous fillers to cellulose cryogels did not favor greater stability since pure cellulose cryogels exposed for 1 year at $180{ }^{\circ} \mathrm{C}$ lose about $15 \%$ of their mass, while samples containing $\mathrm{BC}$ or GNP even lose $80 \%$ or more of their mass. The results of this study shown that only cellulose biomass cryogels are more suitable to produce thermal insulators due to it higher thermal stability.

\section{Acknowledgements}

The authors would like to thank the National Council for Scientific and Technological Development (CNPq) and the Research Support Foundation of the State of Rio Grande do Sul (FAPERGS).

\section{References}

1. Lazzari LK, Zampieri VB, Zanini M, Zattera AJ, Baldasso C. Sorption capacity of hydrophobic cellulose cryogels silanized by two different methods. Cellulose. 2017;24:3421-31.

2. Lazzari LK, Perondi D, Zampieri VB, Zattera AJ, Santana RMC. Cellulose/biochar aerogels with excellent mechanical and thermal insulation properties. Cellulose. 2019;26:9071-83.

3. Jia G, Li Z, Liu P, Jing Q. Preparation and characterization of aerogel/expanded perlite composite as building thermal insulation material. J Non-Cryst Solids. 2018;482:192-202. http://dx.doi.org/10.1016/j.jnoncrysol.2017.12.047

4. Jaxel J, Markevicius G, Rigacci A, Budtova T. Thermal superinsulating silica aerogels reinforced with short man-made cellulose fibers. Compos, Part AAppl Sci Manuf. 2017;103:11321. http://dx.doi.org/10.1016/j.compositesa.2017.09.018.

5. Venkataraman M, Mishra R, Kotresh TM, Militky J, Jamshaid H. Aerogels for thermal insulation in high-performance textiles. Text Prog. 2016;48(2):55-118. 
6. Cuce E, Cuce PM, Wood CJ, Riffat SB. Optimizing insulation thickness and analysing environmental impacts of aerogel-based thermal superinsulation in buildings. Energy Build. 2014;77:2839. http://dx.doi.org/10.1016/j.enbuild.2014.03.034.

7. Walker R, Pavía S. Thermal performance of a selection of insulation materials suitable for historic buildings. Build Environ. 2015;94(P1):155-65. http://dx.doi.org/10.1016/j. buildenv.2015.07.033.

8. Hüsing N, Schubert U. Aerogels - airy materials: chemistry, structure, and properties. Angew Chem Int Ed. 2002;37(1/2):2245.

9. Incropera FP, Dewitt DP, Bergman TL, Lavine AS. Fundamentos de transferência de calor e massa. Rio de Janeiro: LTC; 2007. $657 \mathrm{p}$.

10. Kunz Lazzari L, Perondi D, Zattera AJ, Campomanes Santana RM. Cellulose/biochar cryogels: a study of adsorption kinetics and isotherms. Langmuir. 2021;37(10):3180-8.

11. Ali I, Bahaitham H, Naebulharam R. A comprehensive kinetics study of coconut shell waste pyrolysis. Bioresour Technol. 2017;235:1-11.

12. Neves RM, Ornaghi HL, Zattera AJ, Amico SC. The influence of silane surface modification on microcrystalline cellulose characteristics. Carbohydr Polym. 2020;230:115595. http:// dx.doi.org/10.1016/j.carbpol.2019.115595.

13. Vyazovkin S, Burnham AK, Criado JM, Pérez-Maqueda LA, Popescu C, Sbirrazzuoli N. ICTAC Kinetics Committee recommendations for performing kinetic computations on thermal analysis data. Thermochim Acta. 2011;520(1-2):1-19.

14. Chee A, Lim R, Lai B, Chin F, Abbas Z, Ling K. Kinetic analysis of rice husk pyrolysis using Kissinger-Akahira-Sunose (KAS) method. Procedia Eng. 2016;148:1247-51.

15. Friedman HL. Kinetics of thermal degradation of char-forming plastics from thermogravimetry. Application to a phenolic plastic. J Polym Sci Part C Polym Symp. 1964;6(1):183-95.

16. Neves RM, Ornaghi HL Jr, Ornaghi FG, Amico SC, Zattera AJ. Degradation kinetics and lifetime prediction for polystyrene / nanocellulose nanocomposites. J Therm Anal Calorim. 2022;147:879-90. http://dx.doi.org/10.1007/s10973-020-10316-7.

17. Budrugeac P, Segal E. Application of isoconversional and multivariate non-linear regression methods for evaluation of the degradation mechanism and kinetic parameters of an epoxy resin. Polym Degrad Stabil. 2008;93(6):1073-80.

18. Erceg M, Kresic I, Vrandeic NS, Jakic M. Different approaches to the kinetic analysis of thermal degradation of poly (ethylene oxide). J Therm Anal Calorim. 2017;131(1):325-34.

19. Moukhina E. Determination of kinetic mechanisms for reactions measured with thermoanalytical instruments. J Therm Anal Calorim. 2012;109(3):1203-14.

20. Ourique PA, Ornaghi FG, Ornaghi HL, Wanke CH, Bianchi O. Thermo-oxidative degradation kinetics of renewable hybrid polyurethane-urea obtained from air-oxidized soybean oil. J Therm Anal Calorim. 2019;137(6):1969-79.

21. Tudorachi N, Mustata F. Curing and thermal degradation of diglycidyl ether of bisphenol A epoxy resin crosslinked with natural hydroxy acids as environmentally friendly hardeners. Arab J Chem. 2020;13(1):671-82.

22. Ornaghi HL, Ornaghi FG, Neves RM, Monticeli F, Bianchi O. Mechanisms involved in thermal degradation of lignocellulosic fibers: a survey based on chemical composition. Cellulose. 2020;27(9):4949-61.

23. de Sousa FDB, Zanchet A, Ornaghi Júnior HL, Ornaghi FG. Revulcanization kinetics of waste tire rubber devulcanized by microwaves: challenges in getting recycled tire rubber for technical application. ACS Sustain Chem\& Eng. 2019;7(18):15413-26.

24. Lazzari LK, Perondi D, Zattera AJ, Santana RMC. Influence of the addition of carbon structures in cellulose cryogels. J Porous Mater. 2021:279-88. http://dx.doi.org/10.1007/s10934020-00972-3
25. Hermans PH, Weidinger A. X-ray studies on the crystallinity of cellulose. J Polym Sci, Polym Phys Ed. 1949;4(2):135-44.

26. Cabeza A, Sobrón F, Yedro FM, García-Serna J. Autocatalytic kinetic model for thermogravimetric analysis and composition estimation of biomass and polymeric fractions. Fuel. 2015;148:212 25. http://dx.doi.org/10.1016/j.fuel.2015.01.048.

27. Vyazovkin S, Burnhamb AK, Criadoc JM, Pérez-Maquedac LA, Popescud C, Sbirrazzuoli N. ICTAC Kinetics Committee recommendations for collecting experimental thermal analysis data for kinetic computations. Thermochim Acta. 2011;590(1-2):123.

28. Vyazovkin S, Burnham AK, Favergeon L, Koga N, Moukhina E, Pérez-Maqueda LA, et al. ICTAC Kinetics Committee recommendations for analysis of multi-step kinetics. Thermochim Acta. 2020;689:178597.

29. Pujol D, Liu C, Gominho J, Olivella MÀ, Fiol N, Villaescusa I, et al. The chemical composition of exhausted coffee waste. Ind Crops Prod. 2013;50:423-9.

30. Poletto M, Ornaghi Júnior HL, Zattera AJ. Native cellulose: structure, characterization and thermal properties. Materials (Basel). 2014;7(9):6105-19.

31. Neves RM, Lopes KS, Zimmermann MVG, Poletto M, Zattera AJ. Characterization of polystyrene nanocomposites and expanded nanocomposites reinforced with cellulose nanofibers and nanocrystals. Cellulose [serial on the Internet]. 2019 [cited 2022 Jan 29 ];26(7):4417-29. Available from: http://link.springer. com/10.1007/s10570-019-02392-2

32. Santamarı R, Blanco C, Granda M. Thermal degradation of lignocellulosic materials treated with several acids. J Anal Appl Pyrolysis. 2005;74(1-2):337-43.

33. Lazzari LK, Zampieri VB, Neves RM, Zanini M, Zattera AJ, Baldasso C. A study on adsorption isotherm and kinetics of petroleum by cellulose cryogels. Cellulose. 2018;26(2):1231-46.

34. Sunphorka S, Chalermsinsuwan B, Piumsomboon P. Artificial neural network model for the prediction of kinetic parameters of biomass pyrolysis from its constituents. Fuel. 2017;193:142-58

35. Yao F, Wu Q, Lei Y, Guo W, Xu Y. Thermal decomposition kinetics of natural fibers: activation energy with dynamic thermogravimetric analysis. Polym Degrad Stabil. 2008;93(1):908.

36. Poletto M, Zattera AJ, Forte MMC, Santana RMC. Thermal decomposition of wood: influence of wood components and cellulose crystallite size. Bioresour Technol. 2012;109:148-53. http://dx.doi.org/10.1016/j.biortech.2011.11.122

37. Peng Y, Gardner DJ, Han Y, Kiziltas A, Cai Z, Tshabalala MA. Influence of drying method on the material properties of nanocellulose I: thermostability and crystallinity. Cellulose. 2013;20(5):2379-92.

38. Mo RJ, Zhao Y, Zhao MM, Wu M, Wang C, Li JP, et al. Graphene-like porous carbon from sheet cellulose as electrodes for supercapacitors. Chem Eng J. 2018;346:104-12. http:// dx.doi.org/10.1016/j.cej.2018.04.010

39. Nanda S, Mohanty P, Pant KK, Naik S, Kozinski JA, Dalai AK. Characterization of North American lignocellulosic biomass and biochars in terms of their candidacy for alternate renewable fuels. BioEnergy Res. 2013;6(2):663-77.

40. Yoo S, Kelley SS, Tilotta DC, Park S. Structural characterization of loblolly pine derived biochar by X-ray diffraction and electron energy loss spectroscopy. ACS Sustain Chem\& Eng. 2018;6(2):2621-9.

41. Tang L, Feng Y, He W, Yang F. Combination of graphene oxide with flax-derived cellulose dissolved in $\mathrm{NaOH} /$ urea medium to generate hierarchically structured composite carbon aerogels. Ind Crops Prod. 2019;130:179-83. http://dx.doi.org/10.1016/j. indcrop.2018.12.068.

42. Wan C, Li J. Graphene oxide/cellulose aerogels nanocomposite: Preparation, pyrolysis, and application for electromagnetic 
interference shielding. Carbohydr Polym. 2016;150:172-9. http://dx.doi.org/10.1016/j.carbpol.2016.05.051.

43. Ornaghi HL, Ornaghi FG, Neves RM, Monticeli F, Bianchi O. Mechanisms involved in thermal degradation of lignocellulosic fibers: a survey based on chemical composition. Cellulose. 2020;27(9):4949-61.

44. Zhao J, Xiuwen W, Hu J, Liu Q, Shen D, Xiao R. Thermal degradation of softwood lignin and hardwood lignin by TGFTIR and Py-GC/MS. Polym Degrad Stab. 2014;108:133-8. http://dx.doi.org/10.1016/j.polymdegradstab.2014.06.006.

45. López-Beceiro J, Díaz-Díaz AM, Álvarez-García A, TarríoSaavedra J, Naya S, Artiaga R. The complexity of lignin thermal degradation in the isothermal context. Processes. 2021;9(7):1154.

46. Yu J, Sun L, Ma C, Qiao Y, Yao H. Thermal degradation of PVC: a review. Waste Manag. 2010;48:300-14.

47. Basu P. Biomass gasification and pyrolysis: pratical design and theory. Burlington: Academic Press; 2010. 455 p.

48. Ren F, Li Z, Tan WZ, Liu XH, Sun ZF, Ren PG, et al. Facile preparation of $3 \mathrm{D}$ regenerated cellulose/graphene oxide composite aerogel with high-efficiency adsorption towards methylene blue. J Colloid Interface Sci. 2018;532:58-67. http://dx.doi. org/10.1016/j.jcis.2018.07.101

49. Kwoczynski Z, Čmelík J. Characterization of biomass wastes and its possibility of agriculture utilization due to biochar production by torrefaction process. J Clean Prod. 2021;280:124302. http:// dx.doi.org/10.1016/j.jclepro.2020.124302

50. Benini KCCC, Ornaghi HLJ, Pereira PHF. LJ. M, Woorwald HJC, Cioffi MOH. Survey on chemical, physical, and thermal prediction behaviors for sequential chemical treatments used to obtain cellulose from Imperata Brasiliensis. J Therm Anal Calorim. 2021;143(1):73-85.

51. Pereira PHF, Ornaghi HL, Arantes V, Cioffi MOH. Effect of chemical treatment of pineapple crown fiber in the production, chemical composition, crystalline structure, thermal stability and thermal degradation kinetic properties of cellulosic materials. Carbohydr Res. 2020;2021:499.

52. Hu Y, Liu J, Luo L, Li X, Wang F, Tang K. Kinetics and mechanism of thermal degradation of aldehyde tanned leather. Thermochim Acta. 2020;691:1-13. 


\section{Supplementary material}

The following online material is available for this article:

Table S1 - One-way was performed on $E_{a}$ values for KAS method.

Figure S1 - Plot of Friedman method for all studied samples.

Figure S2 - Plot of KAS method for all studied samples.

Figure S3 - Simulated curves.

Figure S4 - Parameters were obtained after the nonlinear regression method through the thermal degradation mechanism. All fitting presented were R2 $>0.99$ for the best fit. 